\title{
A Three-Dimensional Porous Conducting Polymer Composite with Ultralow Density and Highly Sensitive Pressure Sensing Properties
}

\author{
Jin-Dong Su, ${ }^{1}$ Xian-Sheng Jia, ${ }^{2}$ Jin-Tao Li, ${ }^{2}$ Tao Lou, ${ }^{3}$ Xu Yan, ${ }^{2,4}$ Jia-Lin Sun, ${ }^{1}$ \\ Jun-Hong Chen, ${ }^{1}$ and Yun-Ze Long ${ }^{2,4}$ \\ ${ }^{1}$ School of Material Science \& Engineering, University of Science \& Technology Beijing, Beijing 100083, China \\ ${ }^{2}$ Collaborative Innovation Center for Nanomaterials \& Devices, College of Physics, Qingdao University, Qingdao 266071, China \\ ${ }^{3}$ College of Chemical Science \& Engineering, Qingdao University, Qingdao 266071, China \\ ${ }^{4}$ Industrial Research Institute of Nonwovens \& Technical Textiles, Qingdao University, Qingdao 266071, China
}

Correspondence should be addressed to Jun-Hong Chen; cjh@ustb.edu.cn and Yun-Ze Long; yunze.long@163.com

Received 24 July 2016; Accepted 28 November 2016

Academic Editor: Stefano Bellucci

Copyright (C) 2016 Jin-Dong Su et al. This is an open access article distributed under the Creative Commons Attribution License, which permits unrestricted use, distribution, and reproduction in any medium, provided the original work is properly cited.

\begin{abstract}
An ultralight conducting polyaniline/SiC/polyacrylonitrile (PANI/SiC/PAN) composite was fabricated by in situ polymerization of aniline monomer on the surface of fibers in SiC/PAN aerogel. The SiC/PAN aerogel was obtained by electrospinning, freezedrying, and heat treatment. The ingredient, morphology, structure, and electrical properties of the aerogel before and after in situ polymerization were investigated by X-ray powder diffraction (XRD), Fourier transform infrared spectroscopy (FT-IR), scanning electron microscope (SEM), and voltage-current characteristic measurement. The thermostability of PANI/SiC/PAN composite was investigated by thermogravimetric analysis (TGA) and electrical resistance measured at different temperatures. The density of the PANI/SiC/PAN composite was approximately $0.211 \mathrm{~g} \mathrm{~cm}^{-3}$, the porosity was $76.44 \%$, and the conductivity was $0.013 \mathrm{~S} \mathrm{~m}{ }^{-1}$. The pressure sensing properties were evaluated at room temperature. The electrical resistance of as-prepared sample decreased gradually with the increase of pressure. Furthermore, the pressure sensing process was reversible and the response time was short (about 1s). This composite may have application in pressure sensor field.
\end{abstract}

\section{Introduction}

Various sensors were widely used in all walks of life, and the fabrication of high-performance sensor has drawn extensive attention. Using nanomaterials (nanoparticles $[1,2]$, nanofibers $[3,4]$, nanotubes $[5,6]$, and aerogels $[7,8])$ especially nanofibers or nanofibrous membrane as the element of sensors is effective means to perform high-performance, pint-sized, and lightweight sensors because the low density and high specific surface area can reduce the weight and improve performance of sensor.

Since aerogel was first discovered by Kistler [9] in the 1930s, many efforts have been paid to the development of aerogels because of many kinds of excellent properties. Aerogel, as the lowest density solid material at present, has an extreme porosity of approximately $90 \%-99 \%$. The particular three-dimensional (3D) porous structure made it have good performance in thermal insulation $[10,11]$, absorption of oil [12, 13], catalyst support [14, 15], drug carrier [16], and lithium-ion batteries [17, 18]. Aerogels as gas sensor element have good performance and because of that the large mesopores can provide favorable diffusion for free molecules to move reversibly from the external environment to the pore interior [19]. Nowadays, aerogels have been used in humidity sensing $[19,20]$, oxygen sensing [21], nitrogen dioxide sensing [22] and other sensors. However, most aerogels need to composite conductive materials to enhance conductivity. Polyaniline (PANI), as a conductive polymeric material, has low density, good electrical conductivity, and plasticity. Combining PANI with other materials can obtain good 
conducting composite materials. There are many reports about in situ polymerization of PANI on the surface of organic poly(methyl methacrylate) (PMMA) nanofibers [23], poly(vinylidene fluoride) (PVDF) nanofibers [24], and so on to obtain composite materials which have good sensing property. However there are little reports about in situ polymerization of PANI on the surface of nanofibers in fibrous aerogels.

Here, we used the SiC/polyacrylonitrile (PAN) composite nanofiber aerogels as support to fabricate a porous conducting material with ultralow density by the in situ polymerization of PANI on the surface of fibers in aerogels. The mass increase is $400 \%$ after in situ polymerization. The PANI deposited on the fibers in aerogel and became the majority of PANI/SiC/PAN composite, so the composite has high electrical conductivity. The conductivity of PANI/SiC/PAN composite is about $0.013 \mathrm{~S} \mathrm{~m}^{-1}$. The $3 \mathrm{D}$ porous $\mathrm{PANI} / \mathrm{SiC} / \mathrm{PAN}$ composite is of low density and high porosity. Its density is $0.211 \mathrm{~g} \mathrm{~cm}^{-3}$ and its porosity is $76.44 \%$. The sample has high performance in pressure sensing. The response of pressure is reversible and the response time is short. Under the constant voltage, the current can increase $500 \%$ after pressing for $1 \mathrm{~s}$ and increase $750 \%$ after pressing for $30 \mathrm{~s}$.

\section{Experimental}

2.1. Fabrication of Aerogels. The polyacrylonitrile (PAN) nanofibers were prepared by electrospinning. The electrospinning precursor solution contained $10 \mathrm{wt} \% \operatorname{PAN}\left(M_{w} \sim\right.$ $5,000,000)$ and $90 \mathrm{wt} \%$ DMF (AR). $0.75 \mathrm{wt} \%$ PAN nanofiber membrane, 0.25 wt\% SiC nanowhiskers (diameter of 200$500 \mathrm{~nm}), 20 \mathrm{wt} \%$ tert-butyl alcohol, and $79 \mathrm{wt} \%$ deionized water were put in beakers, and then they were dispersed by high-speed dispersion homogenizer (A-25, China) with $15,000 \mathrm{rpm}$ for $15 \mathrm{~min}$. Then the dispersed mixture was poured into weighing bottles in a plastic box. Liquid nitrogen was poured into plastic box to freeze the solution quickly. Then the weighing bottles with freeze casting PAN/SiC were transferred to freeze-dryer (FD-1-50, China) under $50 \mathrm{~Pa}$ and $-50^{\circ} \mathrm{C}$ for two days. So the $\mathrm{SiC} / \mathrm{PAN}$ aerogels were prepared. The samples have no elasticity, so the samples were put in air dry oven for $300^{\circ} \mathrm{C}$ heating modified to obtain good elasticity and morphological stability.

2.2. In Situ Polymerization of PANI on Fibers in SiC/PAN Aerogel. The PANI/SiC/PAN aerogels were fabricated by the in situ polymerization of PANI on the surface of PAN or SiC fibers. In the progress of in situ polymerization, ammonium persulfate (APS) was used as oxidant and 5-sulfosalicylic acid dihydrate (SSA) was used as catalytic agent, and the aniline was the monomer to form polymer by in situ polymerization. The specific procedures were as follows. Firstly, two solutions were prepared: $4.66 \mathrm{~g}$ APS was dissolved in $100 \mathrm{~mL}$ deionized water marked as solution A and $7.98 \mathrm{~g}$ SSA and $2.26 \mathrm{~g}$ aniline were dissolved in $100 \mathrm{~mL}$ deionized water marked as solution B. Secondly, SiC/PAN aerogels were put into solution B, and then solution A was instilled into solution $\mathrm{B}$ with ultrasonic concussion by ultrasonic vibrating machine (KQ2200DE). Thirdly, the mixed solution was put in freezer at $3^{\circ} \mathrm{C}$ for

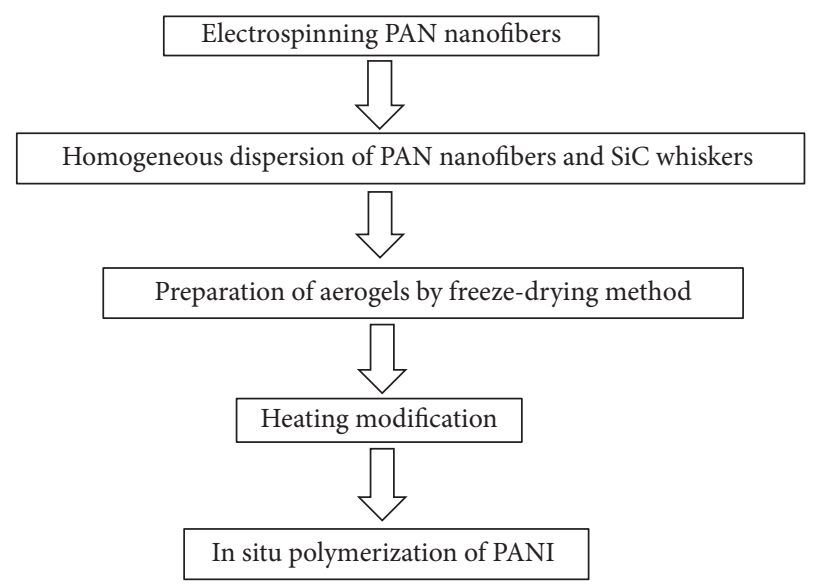

Figure 1: The preparation flow of PANI/SiC/PAN composite.

$24 \mathrm{~h}$. Fourthly, the aerogels were taken out and washed by deionized water. At last, the PANI/SiC/PAN porous composites were dried by natural drying. The fabrication process is shown in Figure 1.

2.3. Pressure Sensing Test. As shown in Figure 2, pressure sensing property was tested by simple homemade device. Two copper wires were fixed on the sides of the sample as electrodes by silver colloids. Then two glass slides were affixed on the sides of the sample to stable the electrodes and suffer the pressure. Two electrodes were connected to Keithley 6487 high resistance meter system to test the change of electrical conductivity. In the process of testing, a constant voltage of $5 \mathrm{~V}$ was supplied, so the changes of instantaneous current can reflect the changes of electrical conductivity of sample under pressures.

2.4. Characterization. The microstructure of aerogel before and after in situ polymerization was measured by a scanning electron microscope (SEM, Nova NanoSEM 450). The sample before polymerization was sputtered with gold and tension of $10 \mathrm{kV}$ was applied. Tension of $20 \mathrm{kV}$ was applied to the sample after polymerization. The thermal stability was detected by thermogravimetric analysis (TGA, MettlerToledo TGA/DSC). The analysis was performed at $10^{\circ} \mathrm{C} \mathrm{min}-1$ from $25^{\circ} \mathrm{C}$ to $500^{\circ} \mathrm{C}$ under air atmosphere. The thermogravimetric analysis testing under air atmosphere is because we want to know the temperature which can be practically used. And the resistances under temperature from $25^{\circ} \mathrm{C}$ to $250^{\circ} \mathrm{C}$ were tested by the High Precision Heating Stage (SET3625, ShenZhen, China) and multimeter; the resistance increased acutely under $225^{\circ} \mathrm{C}$, so the testing was only up to $250^{\circ} \mathrm{C}$ not $500^{\circ} \mathrm{C}$. The phases were identified by X-ray diffraction (XRD, RIGADU D/MAX-2500) in the angular 10-90 with a scan speed of $4^{\circ} \mathrm{min}^{-1}$. The chemical compositions were analyzed by Fourier transform infrared spectroscopy (FTIR) using a Thermo Scientific Nicolet iN10 spectrometer and transmittance data were processed for the wave number range $700-4000 \mathrm{~cm}^{-1}$. The conductivities of the sample before and 


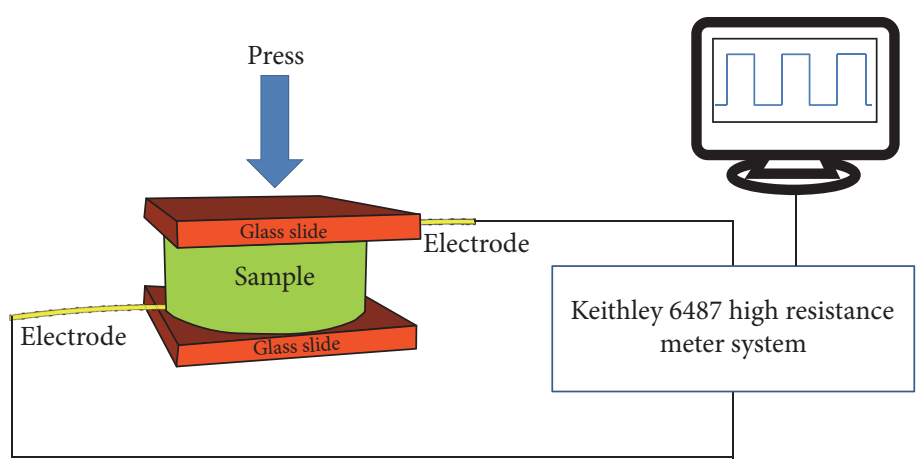

FIGURE 2: Diagrammatic drawing of pressure testing equipment.

TABLE 1: Morphology, conductivity, and porosity changes of the aerogel after in situ polymerization.

\begin{tabular}{lccccc}
\hline & Diameters $(\mathrm{cm})$ & Height $(\mathrm{cm})$ & Weight $(\mathrm{g})$ & Conductivity $\left(\mathrm{S} \mathrm{m} \mathrm{m}^{-1}\right)$ & Porosity $(\%)$ \\
\hline Before polymerization & 2 & 1.1 & 0.0323 & $2.9 \times 10^{-8}$ & 99.24 \\
After polymerization & 1.2 & 0.6 & 0.1623 & $1.3 \times 10^{-2}$ & 76.44 \\
\hline
\end{tabular}

after in situ polymerization were calculated from voltagecurrent curves measured by a Keithley 6487 high resistance meter system.

\section{Results and Discussion}

The conducting aerogel was prepared by the in situ polymerization of PANI on the surface of fibers in the aerogels. The pores (diameter of about $1 \mu \mathrm{m}$ ) in as-prepared PAN/SiC aerogel are bigger than pores in common aerogels, so the PANI is more easily polymerized in the inside of aerogel and the coating layer of PANI can be thicker. We can see that the color of the sample was translated to bottle green as shown in Figure 3, and it is due to the PANI being bottle green. In fact, in the process of polymerization of PANI, the solution and the sample changed color gradually. And the color of sample would not change back after cleaning by deionized water. It indicated that the PANI was in situ polymerization on the surface of fibers in aerogel firmly and stably. It can be seen from Figure 3(b) that there is shrinkage after polymerization compared with original aerogel. It should be noted that the shrinkage of the sample happened in the process of drying, and there are almost no changes of shape and volume in the process of polymerization and washing. The shrinkage may be due to the surface tension of water in the process of drying. The weight of the sample was increased from $0.0323 \mathrm{~g}$ to $0.1623 \mathrm{~g}$; the increase of relative mass is $400 \%$. So the density after polymerization was increased (about $0.211 \mathrm{~g} \mathrm{~cm}^{-3}$ ). The porosity of aerogel was calculated by the formula $P=(1-$ $\left.\rho_{b} / \rho_{s}\right) \times 100 \%$. Here, $\rho_{b}$ is the bulk density, $\rho_{s}$ is the skeletal density, and $P$ is the porosity. The porosity of PANI/SiC/PAN composite was $76.44 \%$.

The $I-V$ curves of the sample before and after in situ polymerization were shown in Figure 4 . The resistance of sample after polymerization was increased $2 \times 10^{7}$ times compared with the original sample. The specific morphology change of aerogel after polymerization was shown in Table 1 . The conductivity changes were not equal to resistance change because of the shrinkage of sample. The specific conductivity was changed from $2.9 \times 10^{-8} \mathrm{~S} \mathrm{~m}^{-1}$ to $1.3 \times 10^{-2} \mathrm{~S} \mathrm{~m}^{-1}$ calculated by the formula $G=I / \rho=S / R L$; here $G$ is the conductivity, $\rho$ is the specific resistance, $S$ is the area of surface, $R$ is the resistance, and $L$ is the length.

The FI-IR spectra of the sample before and after in situ polymerization are shown in Figure 5(a). The measurement range was $700-4000 \mathrm{~cm}^{-1}$. The $\mathrm{SiC} / \mathrm{PAN}$ aerogel spectra (curve (A)) exhibited the absorption peaks of a stretching vibration at peaks at $2933 \mathrm{~cm}^{-1}(\mathrm{CH}$ stretching in $\mathrm{CH}$ and $\mathrm{CH}_{2}$ groups), $2242 \mathrm{~cm}^{-1}(\mathrm{C} \equiv \mathrm{N}), 1451 \mathrm{~cm}^{-1}$ ( $\mathrm{CH}$ blending), and $1119 \mathrm{~cm}^{-1}$ (ether band) $[25,26]$, and those four peaks that come from PAN nanofibers cannot be observed in the spectrum of PANI/SiC/PAN composites which may due to the PAN nanofibers being clad by PANI. Absorption peaks at $802 \mathrm{~cm}^{-1}$ and $917 \mathrm{~cm}^{-1}$ are ascribed to the transversal optic (TO) mode and longitudinal optical (LO) vibration of the Si-C stretching vibration [27]. Those two peaks were weakened after polymerization. The characteristic peaks at $1657 \mathrm{~cm}^{-1}$ and $1567 \mathrm{~cm}^{-1}$ are attributed to the stretching vibration of quinoid and benzenoid rings on PANI molecular chain, respectively [28]. The peak observed at $1080 \mathrm{~cm}^{-1}$ is designated to vibration mode of $\mathrm{N}=\mathrm{Q}=\mathrm{N}$ which is an electronic band ( $Q$ refers to the quinonic type rings) [29]. The C-H vibration of aromatic ring at $3059 \mathrm{~cm}^{-1}$ and $\mathrm{C}-\mathrm{N}$ of from aromatic amines at $1297 \mathrm{~cm}^{-1}[30]$ were also observed in curve (B). All those peaks proved the in situ polymerization of PANI on the surface of fibers in aerogels.

The XRD patterns of the sample before and after in situ polymerization are shown in Figure 5(b). The peak at $2 \theta$ values of $16-17^{\circ}$ is related to PAN [31], which can both be observed from curve (A) and curve (B). The peaks at 35.9, 41.6, 60.1, and 71.9 corresponded to (111), (200), (220), and (311) crystal planes of 3C-SiC [32], which can also be both observed from curve (A) and curve (B). The crystalline peaks appear at $2 \theta=15.2,20.7$, and 25.4, corresponding to (011), 


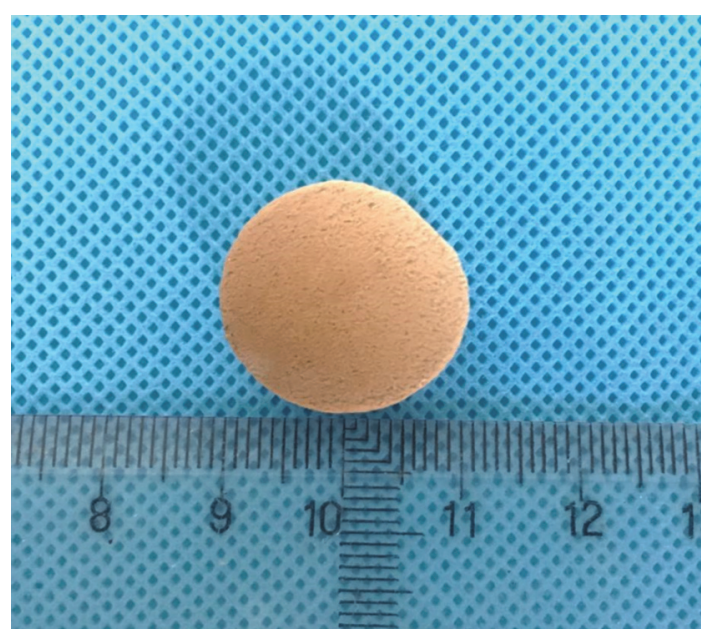

(a)

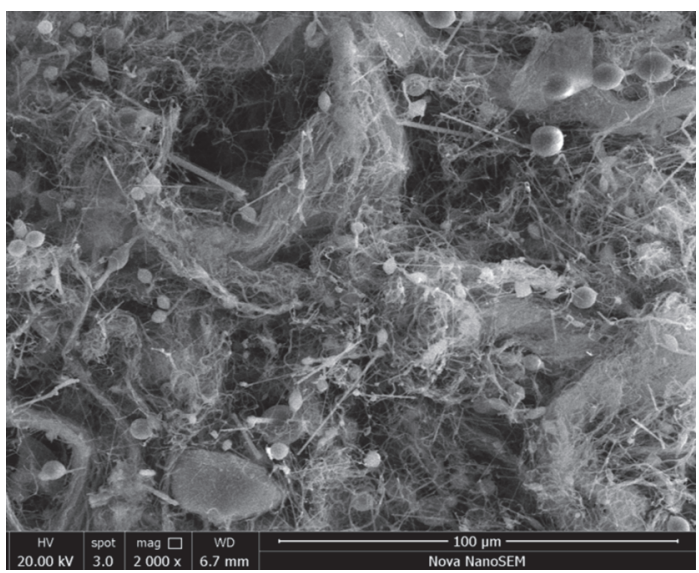

(c)

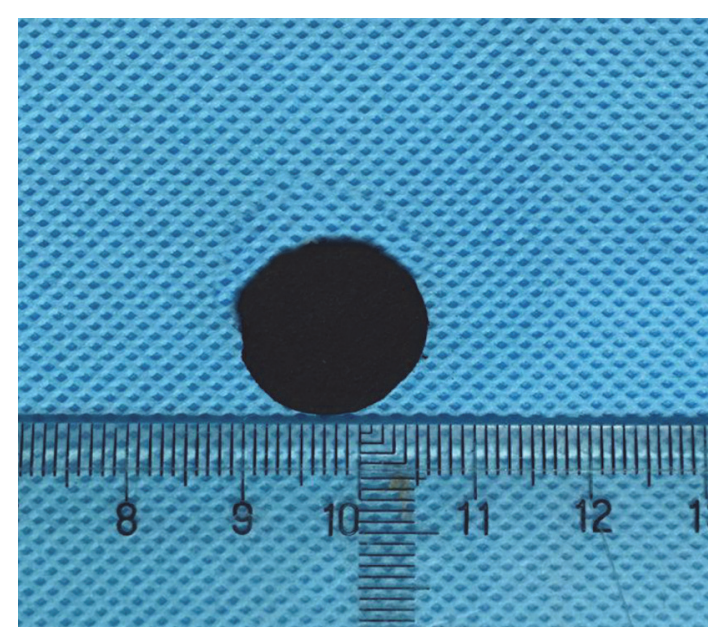

(b)

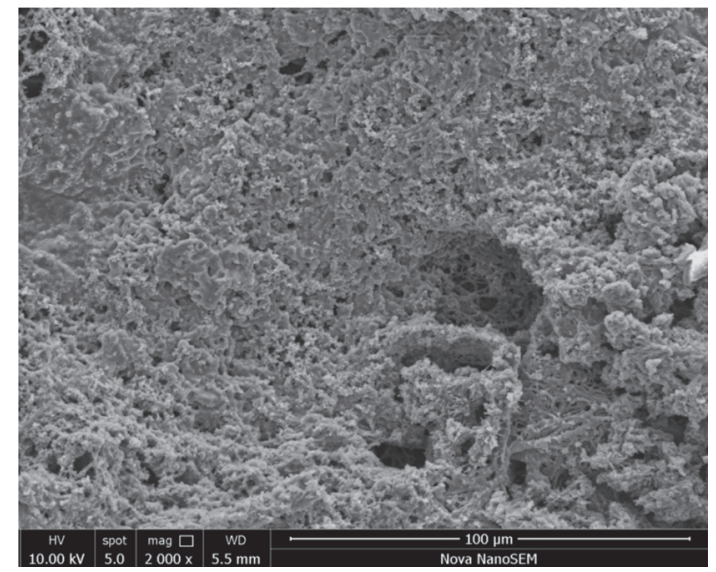

(d)

FIGURE 3: Photographs of (a) PAN/SiC aerogel and (b) PANI/SiC/PAN composite and SEM images of (c) PAN/SiC aerogel and (d) porous $\mathrm{PANI} / \mathrm{SiC} / \mathrm{PAN}$ composite.

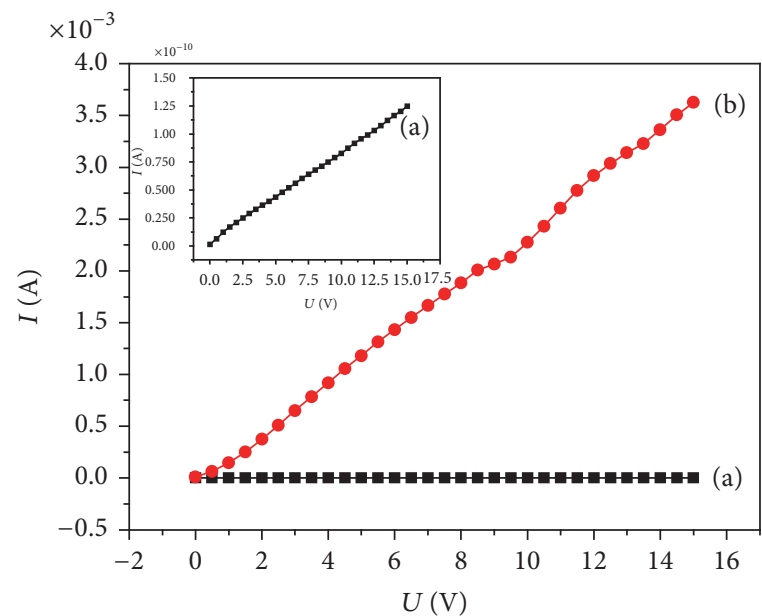

FIgURE 4: The $I-V$ curve of sample before (a) and after in situ polymerization (b). The detail of curve (a) was shown in top left corner. 


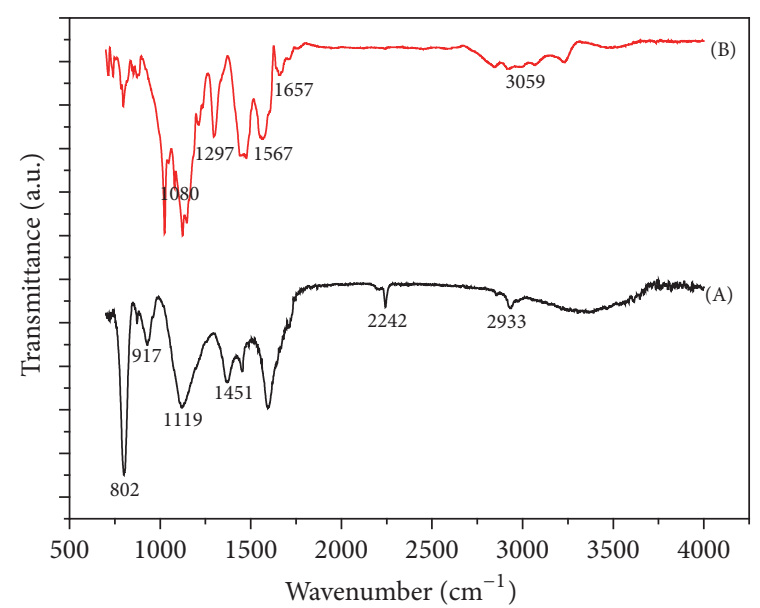

(a)

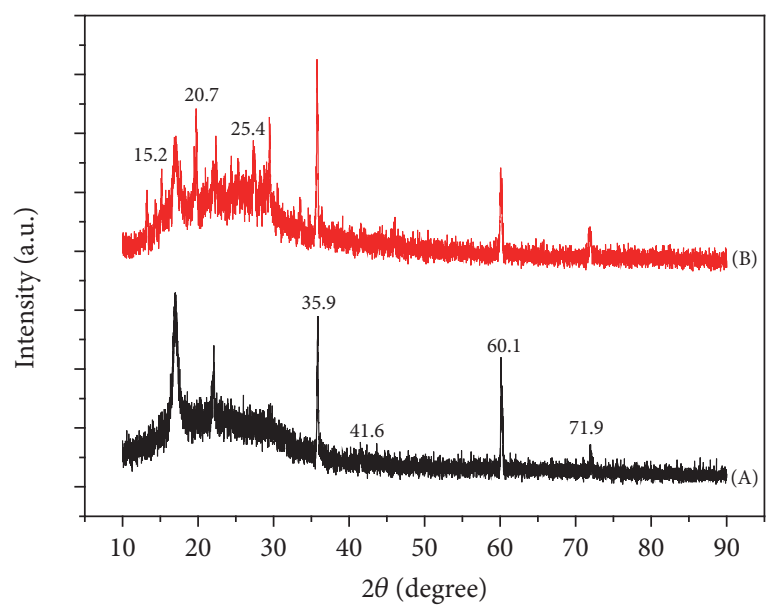

(b)

FIGURE 5: (a) FT-IR spectra and (b) XRD patterns of (A) SiC/PAN aerogel and (B) PANI/SiC/PAN composite.

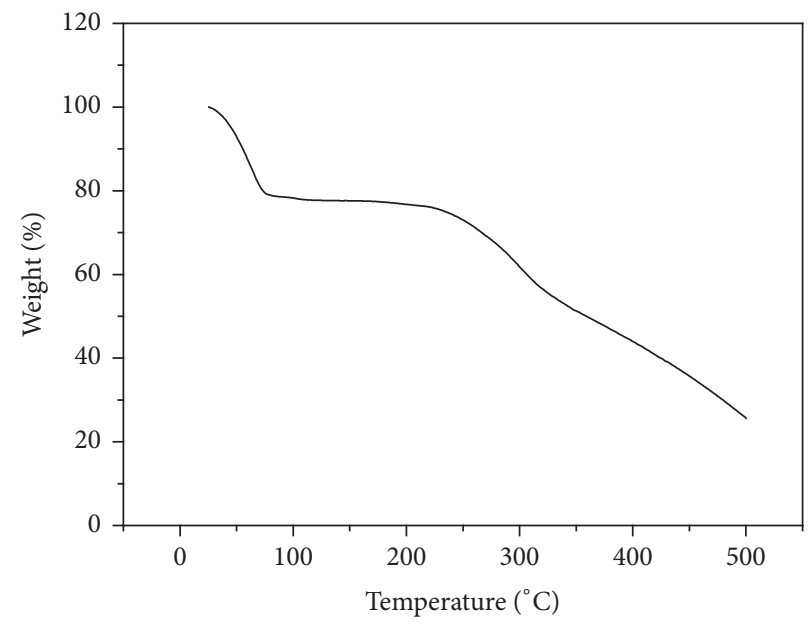

(a)

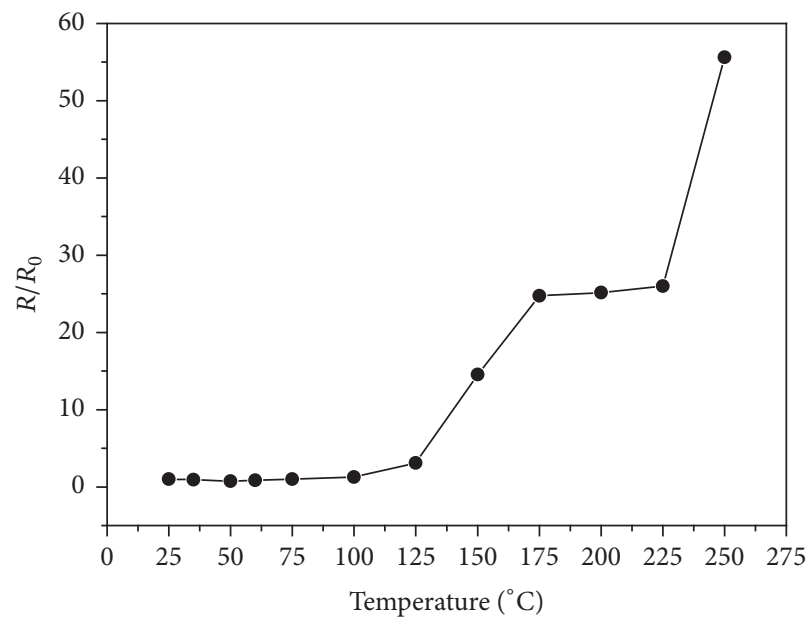

(b)

FIgURE 6: (a) TG curve and (b) the resistance variation with increasing temperature of PANI/SiC/PAN composite.

(020), and (200) crystal planes of PANI, respectively [33], which can observed from curve (B). All the peaks illustrate the existence of $\mathrm{SiC}, \mathrm{PAN}$, and PANI.

The thermogravimetric (TG) curve of PANI/SiC/PAN is shown in Figure 6(a). The weight loss from room temperature to $78^{\circ} \mathrm{C}$ is due to the presence of moisture. The $\mathrm{PANI} / \mathrm{SiC} / \mathrm{PAN}$ composite can absorb a large number of water molecules because of the high porosity. The obvious weight loss from $234^{\circ} \mathrm{C}$ to $500^{\circ} \mathrm{C}$ is attributed to the degradation polymer backbone of PANI [34] and the pyrolysis of PAN [35].

Figure 6(b) shows the resistance variation with increasing temperature from $25^{\circ} \mathrm{C}$ to $250^{\circ} \mathrm{C}$ of $\mathrm{PANI} / \mathrm{SiC} / \mathrm{PAN}$ composite. The increase of resistance from $50^{\circ} \mathrm{C}$ to $100^{\circ} \mathrm{C}$ may be due to the water evaporation because water can increase the electrical conductivity of polyaniline through an increase in the interchain electron transfer and/or by increasing the mobility of dopant ions [36-38]. The increase of resistance beyond $100^{\circ} \mathrm{C}$ is due to the pyrolysis of PANI. The pyrolysis of PANI is drastic after $234^{\circ} \mathrm{C}$ as shown in Figure $6(\mathrm{a})$ and the increase of resistance is also drastic from $225^{\circ} \mathrm{C}$ to $250^{\circ} \mathrm{C}$.

To test the pressure sensing property, the resistances of the sample under different pressures at $10^{-3}$ bar levels were tested. As shown in Figure 7, the imposed pressures were from 0.001 to 0.010 bar. The electrical resistivity declined gradually with the increase of pressure. And the decrease of resistance was about $18 \%$ and even the pressure was only 0.002 bar. So the sample can detect the light contact pressure at $10^{-3}$ bar levels. The change of electrical resistance was nonlinear may be due to the fact that the closing of pore was not completely in proportion to the pressure.

The reversible pressure sensing property of sample was also tested. A constant voltage of $5 \mathrm{~V}$ was applied on the sample, so the electric current reflects the change of resistance. The test period was $60 \mathrm{~s}$ ( $30 \mathrm{~s}$ for pressure and $30 \mathrm{~s}$ for relax). As shown in Figure 8(a), when the sample was pressed by the 


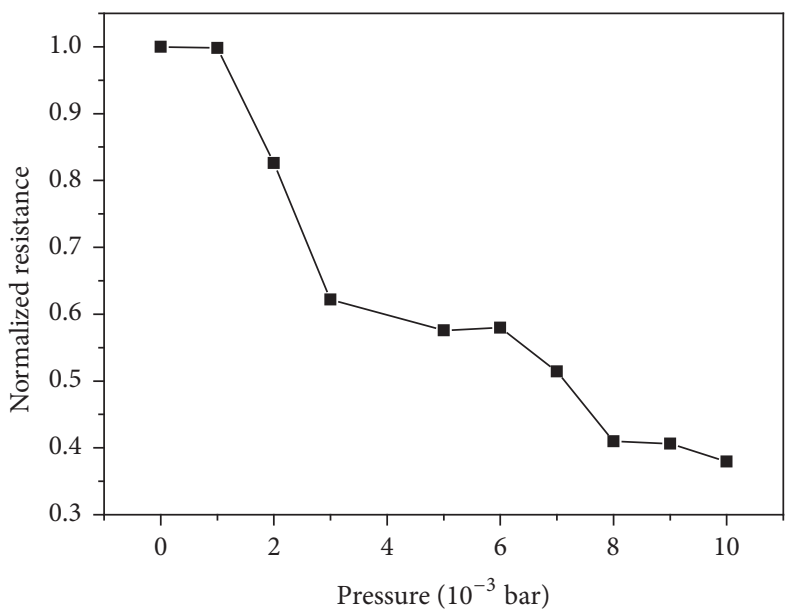

FIGURE 7: The resistances under different pressures at $10^{-3}$ bar levels.

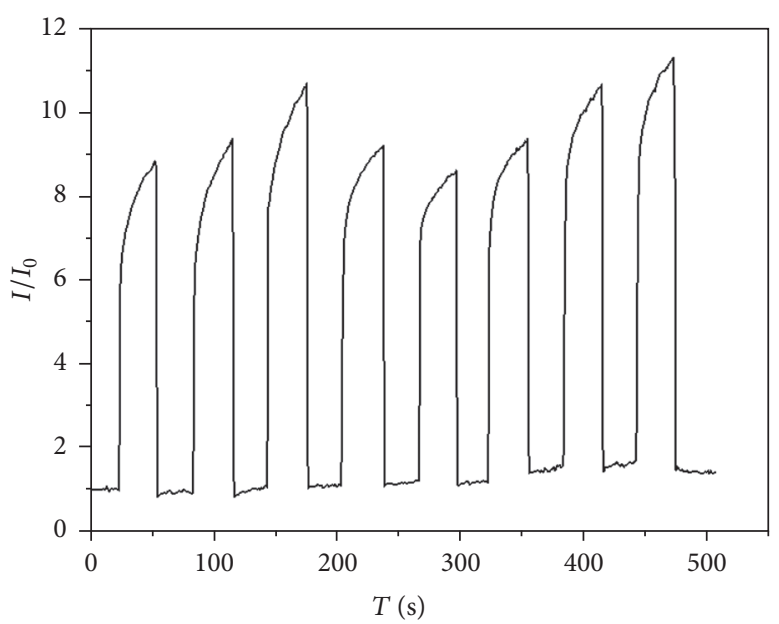

(a)

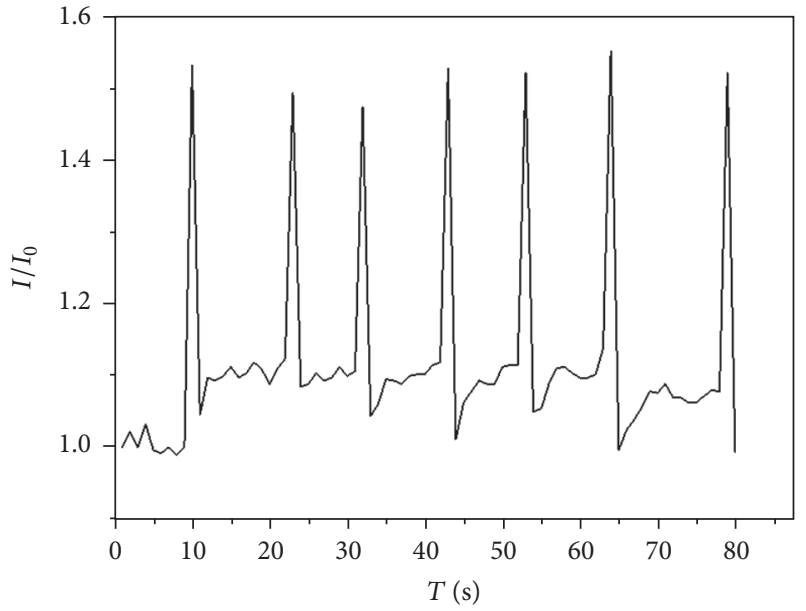

(b)

FIGURE 8: The reversible response curves (a) and the instantaneous response curves (b) of electric current to the pressure.

pressure of 0.02 bar, the current increased clearly. The current rise quickly at first; the increase of current was up to about $500 \%$ when the sample was pressed for $1 \mathrm{~s}$. Then the current rise rate was slowed down. The increase was up to $750 \%$ when the sample was pressed for $30 \mathrm{~s}$. When the sample was relaxed, the resistance was regained. So the response to pressure was fast and reversible.

The instantaneous response of pressure was also tested. The means is similar to the reversible response testing; a constant voltage of $5 \mathrm{~V}$ was supplied on the sides of sample. But in order to obtain quick pressure and recovery, we use index finger to press sample in a very short time. Figure 8 (b) shows the response curve of instantaneous pressure. The response and recovery time is quite short, and the response of current is clear (increased by about 50\%). There is a little increase (about 10\%) of current after pressing and recover compared with the original current, and it may be due to the unrecoverable deformation in the process of testing.

Figure 9 shows the diagrammatic drawing of pores changing in the process of pressing and relaxing. After in situ polymerization the fibers were packaged by PANI. The fiber became thicker and the pores became tiny. The electric current was conducted from one fiber to another in the sample. Under the effect of pressure, the sample deformation occurred. A portion of pores was closed when the sample was pressed while they were open when the pressure was canceled. The closure of pores can connect conducting fibers so the electrical conductivity of sample increased with the pressure. The shape changes become bigger and the closed pores become more with the increase of pressure, so the electrical conductivity becomes higher with the increase of pressure.

\section{Conclusion}

Here, a 3D porous conducting material was prepared by a simple and efficient method-in situ polymerization of PANI on the surface of fibers in the aerogels. After polymerization of PANI, the weight was increased by $400 \%$. And its 


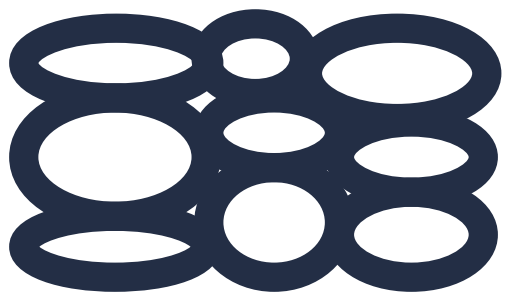

(a)

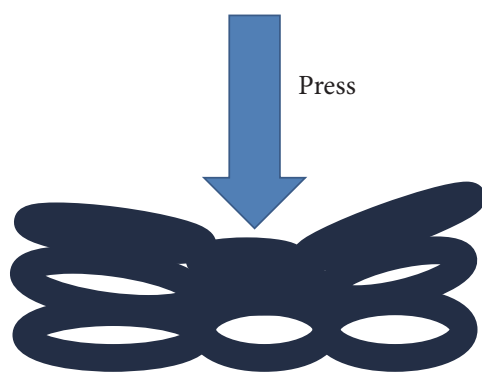

(b)

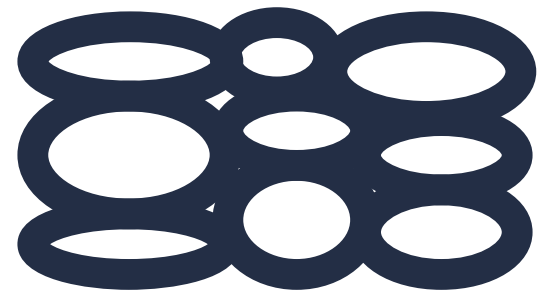

(c)

FIGURE 9: Diagrammatic drawing of changing process of pores when pressed and relaxed.

density was still low (about $0.211 \mathrm{~g} \mathrm{~cm}^{-3}$ ). The porosity of $\mathrm{PANI} / \mathrm{SiC} / \mathrm{PAN}$ composite is $76.44 \%$, and the conductivity of it is $0.013 \mathrm{~S} \mathrm{~m}^{-1}$. The sample has good pressure sensing property because of its porousness and good conductivity. The pressure sensing property was tested by homemade simple device. The resistance of sample was reduced gradually after the increase of pressure. The response is reversible and the response time is short, so the composite can detect even instantaneous or tiny pressure. The 3D porous conducting $\mathrm{PANI} / \mathrm{SiC} / \mathrm{PAN}$ composite material may be used in pressure sensors.

\section{Competing Interests}

The authors declare that they have no competing interests.

\section{Authors' Contributions}

Jin-Dong Su and Xian-Sheng Jia contributed to this work equally.

\section{Acknowledgments}

This work was supported by the National Natural Science Foundation of China (51673103, 51373082, and 51572019), the Taishan Scholars Programme of Shandong Province, China (ts20120528), Innovative Research Team in University (IRT1207), and the Postdoctoral Scientific Research Foundation of Qingdao.

\section{References}

[1] N. Nath and A. Chilkoti, "A colorimetric gold nanoparticle sensor to interrogate biomolecular interactions in real time on a surface," Analytical Chemistry, vol. 74, no. 3, pp. 504-509, 2002.

[2] S. Mubeen, T. Zhang, B. Yoo, M. A. Deshusses, and N. V. Myung, "Palladium nanoparticles decorated single-walled carbon nanotube hydrogen sensor," The Journal of Physical Chemistry C, vol. 111, no. 17, pp. 6321-6327, 2007.

[3] J. P. Cheng, B. B. Wang, M. G. Zhao, F. Liu, and X. B. Zhang, "Nickel-doped tin oxide hollow nanofibers prepared by electrospinning for acetone sensing," Sensors and Actuators B: Chemical, vol. 190, pp. 78-85, 2014.
[4] Z. Y. Pang, J. P. Fu, L. Luo, F. L. Huang, and Q. F. Wei, "Fabrication of $\mathrm{PA} 6 / \mathrm{TiO}_{2} / \mathrm{PANI}$ composite nanofibers by electrospinning-electrospraying for ammonia sensor," Colloids and Surfaces A: Physicochemical and Engineering Aspects, vol. 461, no. 1, pp. 113-118, 2014.

[5] S. An, S. Park, H. Ko, and C. Lee, "Fabrication of $\mathrm{WO}_{3}$ nanotube sensors and their gas sensing properties," Ceramics International, vol. 40, no. 1, pp. 1423-1429, 2014.

[6] Z. H. Li, D. Y. Ding, Q. Liu, C. Q. Ning, and X. W. Wang, "Ni-doped $\mathrm{TiO}_{2}$ nanotubes for wide-range hydrogen sensing," Nanoscale Research Letters, vol. 9, article 118, 2014.

[7] T. Alizadeh and F. Ahmadian, "Thiourea-treated graphene aerogel as a highly selective gas sensor for sensing of trace level of ammonia," Analytica Chimica Acta, vol. 897, pp. 87-95, 2015.

[8] X. H. Lou, C. L. Zhu, H. Pan et al., "Cost-effective three-dimensional graphene/Ag aerogel composite for high-performance sensing," Electrochimica Acta, vol. 205, pp. 70-76, 2016.

[9] S. S. Kistler, "Coherent expanded aerogels," Journal of Physical Chemistry, vol. 36, no. 1, pp. 52-64, 1932.

[10] M. Reim, W. Körner, J. Manara et al., "Silica aerogel granulate material for thermal insulation and daylighting," Solar Energy, vol. 79, no. 2, pp. 131-139, 2005.

[11] S. T. Nguyen, J. Feng, S. K. Ng, J. P. W. Wong, V. B. C. Tan, and H. M. Duong, "Advanced thermal insulation and absorption properties of recycled cellulose aerogels," Colloids and Surfaces A: Physicochemical and Engineering Aspects, vol. 445, pp. 128134,2014

[12] S. F. Chin, A. N. B. Romainor, and S. C. Pang, "Fabrication of hydrophobic and magnetic cellulose aerogel with high oil absorption capacity," Materials Letters, vol. 115, pp. 241-243, 2014.

[13] Z.-Y. Wu, C. Li, H.-W. Liang et al., "Carbon nanofiber aerogels for emergent cleanup of oil spillage and chemical leakage under harsh conditions," Scientific Reports, vol. 4, article no. 4079, 2014.

[14] E. Guilminot, F. Fischer, M. Chatenet et al., "Use of cellulosebased carbon aerogels as catalyst support for PEM fuel cell electrodes: electrochemical characterization," Journal of Power Sources, vol. 166, no. 1, pp. 104-111, 2007.

[15] A. Smirnova, X. Dong, H. Hara, A. Vasiliev, and N. Sammes, "Novel carbon aerogel-supported catalysts for PEM fuel cell application," International Journal of Hydrogen Energy, vol. 30, no. 2, pp. 149-158, 2005.

[16] T. Mehling, I. Smirnova, U. Guenther, and R. H. H. Neubert, "Polysaccharide-based aerogels as drug carriers," Journal of Non-Crystalline Solids, vol. 355, no. 50-51, pp. 2472-2479, 2009. 
[17] B. Qiu, M. Xing, and J. Zhang, "Mesoporous TiO2 nanocrystals grown in situ on graphene aerogels for high photocatalysis and lithium-ion batteries," Journal of the American Chemical Society, vol. 136, no. 16, pp. 5852-5855, 2014.

[18] L. Yin, Z. Zhang, Z. Li et al., "Spinel $\mathrm{ZnMn}_{2} \mathrm{O}_{4}$ nanocrystalanchored 3D hierarchical carbon aerogel hybrids as anode materials for lithium ion batteries," Advanced Functional Materials, vol. 24, no. 26, pp. 4176-4185, 2014.

[19] C.-T. Wang, C.-L. Wu, I.-C. Chen, and Y.-H. Huang, "Humidity sensors based on silica nanoparticle aerogel thin films," Sensors and Actuators B: Chemical, vol. 107, no. 1, pp. 402-410, 2005.

[20] C.-T. Wang and C.-L. Wu, "Electrical sensing properties of silica aerogel thin films to humidity," Thin Solid Films, vol. 496, no. 2, pp. 658-664, 2006.

[21] M. R. Ayers and A. J. Hunt, "Molecular oxygen sensors based on photoluminescent silica aerogels," Journal of Non-Crystalline Solids, vol. 225, no. 1-3, pp. 343-347, 1998.

[22] R. X. Wang, G. L. Li, Y. Q. Dong, Y. W. Chi, and G. N. Chen, "Carbon quantum dot-functionalized aerogels for $\mathrm{NO}_{2}$ gas sensing," Analytical Chemistry, vol. 85, no. 17, pp. 8065-8069, 2013.

[23] H.-D. Zhang, C.-C. Tang, Y.-Z. Long et al., "High-sensitivity gas sensors based on arranged polyaniline/PMMA composite fibers," Sensors and Actuators A: Physical, vol. 219, pp. 123-127, 2014.

[24] G.-F. Yu, X. Yan, M. Yu et al., "Patterned, highly stretchable and conductive nanofibrous PANI/PVDF strain sensors based on electrospinning and in situ polymerization," Nanoscale, vol. 8, no. 5, pp. 2944-2950, 2016.

[25] C. Q. Zhang, Q. B. Yang, N. Q. Zhan et al., "Silver nanoparticles grown on the surface of PAN nanofiber: preparation, characterization and catalytic performance," Colloids and Surfaces A: Physicochemical and Engineering Aspects, vol. 362, no. 1-3, pp. 58-64, 2010.

[26] K. Saeed, S. Haider, T.-J. Oh, and S.-Y. Park, "Preparation of amidoxime-modified polyacrylonitrile (PAN-oxime) nanofibers and their applications to metal ions adsorption," Journal of Membrane Science, vol. 322, no. 2, pp. 400-405, 2008.

[27] P. Hu, R. Pan, S. Dong, K. Jin, and X. Zhang, "Several millimeters long $\mathrm{SiC}-\mathrm{SiOx}$ nanowires synthesized by carbon black and silica sol," Ceramics International, vol. 42, no. 2, pp. 3625-3630, 2016.

[28] J. H. Luo, P. Shen, W. Yao, C. F. Jiang, and J. G. Xu, "Synthesis, characterization, and microwave absorption properties of reduced graphene oxide/strontium ferrite/polyaniline nanocomposites," Nanoscale Research Letters, vol. 11, no. 1, article 141, 2016.

[29] Y. Zhao and C. Wang, "Extremely facile synthesis of manganese dioxide-polyaniline nano-reticulation with enhanced electrochemical properties," Journal of Alloys and Compounds, vol. 677, pp. 281-287, 2016.

[30] P. C. Rodrigues, M. P. Cantão, P. Janissek et al., "Polyaniline/lignin blends: FTIR, MEV and electrochemical characterization," European Polymer Journal, vol. 38, no. 11, pp. 2213-2217, 2002.

[31] H. K. Shin, M. Park, H.-Y. Kim, and S.-J. Park, "Influence of orientation on ordered microstructure of PAN-based fibers during electron beam irradiation stabilization," Journal of Industrial and Engineering Chemistry, vol. 32, pp. 120-122, 2015.

[32] J. H. Chen, W. N. Liu, T. Yang et al., "A facile synthesis of a threedimensional flexible 3C-SiC sponge and its wettability," Crystal Growth \& Design, vol. 14, no. 9, pp. 4624-4630, 2014.
[33] J. Yan, T. Wei, B. Shao et al., "Preparation of a graphene nanosheet/polyaniline composite with high specific capacitance," Carbon, vol. 48, no. 2, pp. 487-493, 2010.

[34] C. Merlini, G. M. O. Barra, S. D. A. S. Ramoa et al., "Electrically conductive polyaniline-coated electrospun poly(vinylidene fluoride) mats," Frontiers in Materials, vol. 2, 2015.

[35] T. J. Xue, M. A. McKinney, and C. A. Wilkie, "The thermal degradation of polyacrylonitrile," Polymer Degradation and Stability, vol. 58, no. 1-2, pp. 193-202, 1997.

[36] S. T. McGovern, G. M. Spinks, and G. G. Wallace, "Microhumidity sensors based on a processable polyaniline blend," Sensors and Actuators B: Chemical, vol. 107, no. 2, pp. 657-665, 2005.

[37] M. J. Winokur and B. R. Mattes, "Structural studies of halogen acid doped polyaniline and the role of water hydration," Macromolecules, vol. 31, no. 23, pp. 8183-8191, 1998.

[38] K. Ogura, T. Saino, M. Nakayama, and H. Shiigi, "The humidity dependence of the electrical conductivity of a soluble polyaniline-poly(vinyl alcohol) composite film," Journal of Materials Chemistry, vol. 7, no. 12, pp. 2363-2366, 1997. 

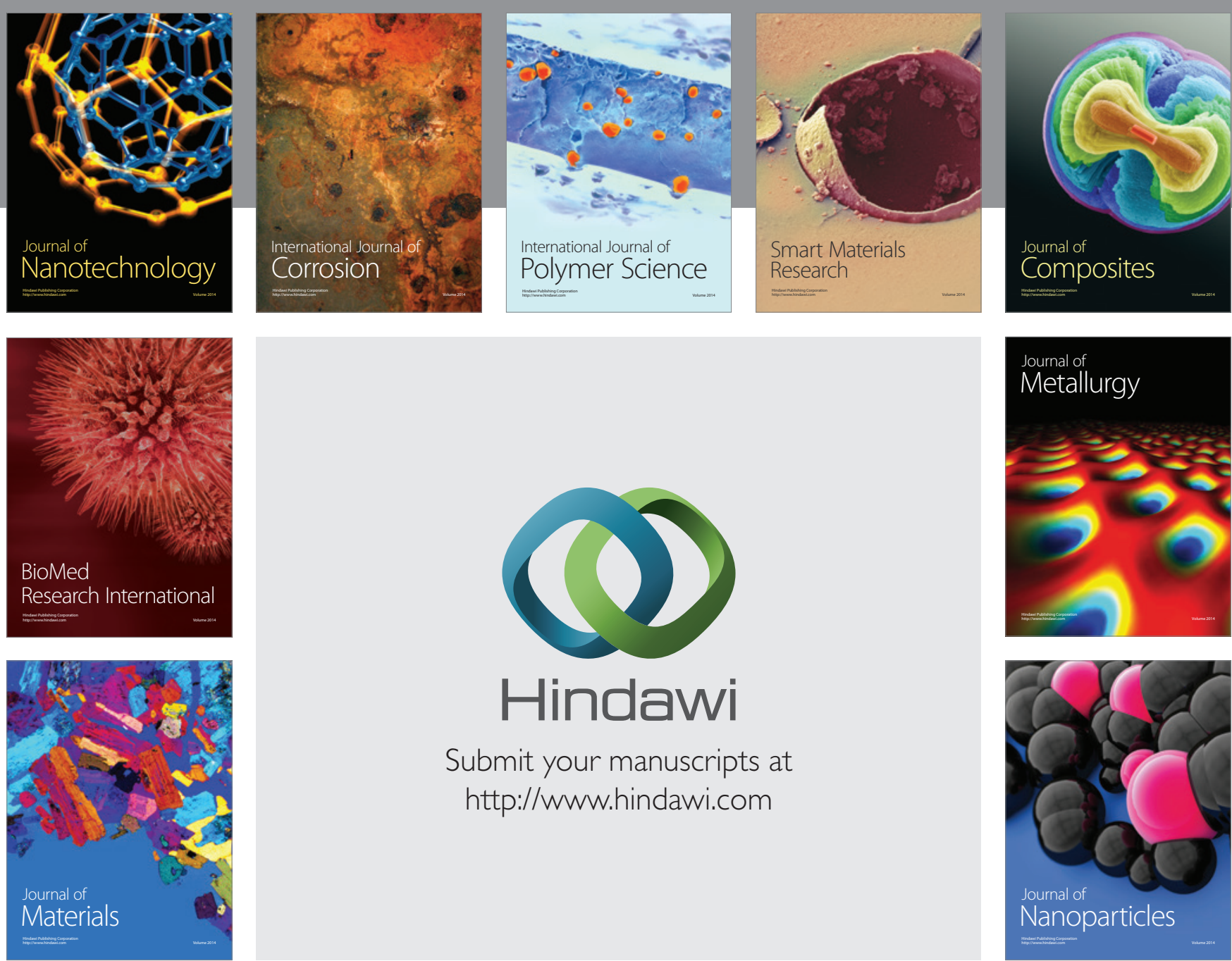

\section{Hindawi}

Submit your manuscripts at

http://www.hindawi.com

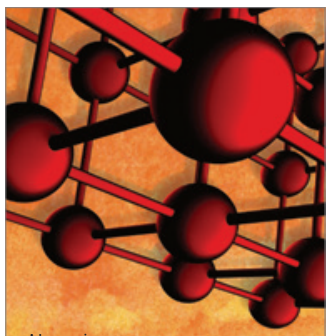

Materials Science and Engineering
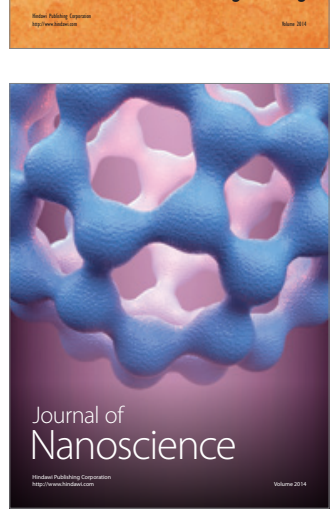
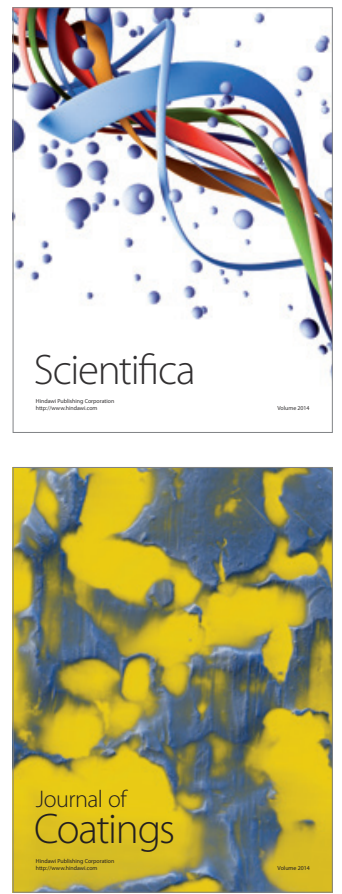
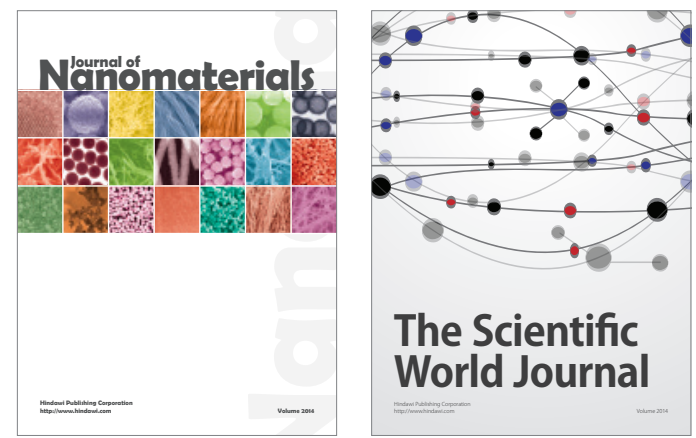

The Scientific World Journal
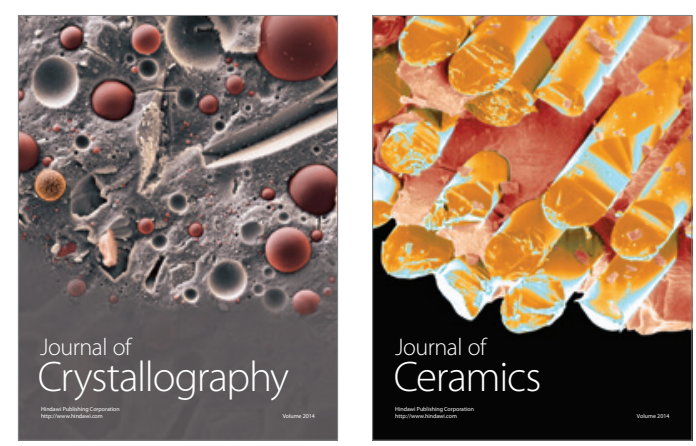
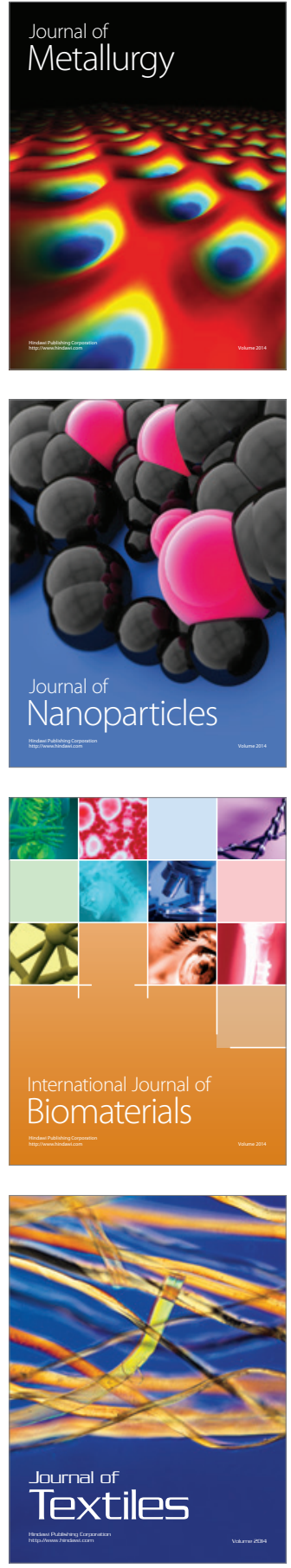